\title{
Dehiscence of Lamina Papyracea a Normal Variation: A Case Report in
}

\section{Iran}

\author{
Masoumeh Akbari ${ }^{1}$ and Narges Alizade (iD) ${ }^{2,}{ }^{*}$ \\ ${ }^{1}$ Spiritual Health Research Center, Faculty of Paramedicince, Qom University of Medical Sciences, Qom, Iran \\ ${ }^{2}$ Faculty of Medicine, Qom University of Medical Sciences, Qom, Iran \\ "Corresponding author: Otolaryngology Specialist, Assistant Professor, Faculty of Medicine, Qom University of Medical Sciences, Qom, Iran. Tel: +98-9127156025. Email: \\ narali1360@gmail.com \\ Received 2018 September 08; Revised 2018 December 26; Accepted 2019 January 01.
}

\begin{abstract}
Introduction: The dehiscence of lamina papyracea (LP) is an anatomic variation of ethmoid bone that is important in endoscopic sinus surgery.

Case Presentation: There are two different cases without a history of trauma. Entrapment of fat was observed without the involvement of medial rectus muscle. The variations of paranasal sinuses are common, and certain types of them are very important; for instance, the position of LP, whether medial or lateral, or the dehiscence of LP therefore regarding the position of LP in sinus surgery can prevent complications of orbit.

Conclusions: Awareness of dehiscence of LP before surgery is crucial for preventing orbital complications. The present study describes two cases with medial positions and dehiscence of LP.
\end{abstract}

Keywords: Lamina Papyracea, Paranasal Sinuses, Sinus Surgery

\section{Introduction}

The ethmoid bone is the site of anatomic changes (1) The anomaly of the ethmoid bone recognized on skull dissection long before is the dehiscence of the lamina papyracea (LP) (1). The orbit and paranasal sinuses vary not only among individuals, but also between the two sides of an individual (2). Using the tomography of paranasal sinuses is very useful for diagnosing the variations and anatomy of sinuses before surgery. To determine the position of LP in the present study as well as in the study by Herzalla et al. (3), the distance between the vertical line passing through the inferior margin of the planned middle meatal antrostomy (MMA) and the inferior turbinate attached to the lateral nasal wall was measured along with the medial border of the LP (3). Herzalla et al. (3) found the position of LP to lies either within $2 \mathrm{~mm}$ on either side of the MMA inferior margin (type I), more than $2 \mathrm{~mm}$ medial to the MMA line (type IIa: $2-4 \mathrm{~mm}$; type IIb: $>4 \mathrm{~mm}$ ), or more than $2 \mathrm{~mm}$ lateral to the MMA line (type IIIa: 2 - $4 \mathrm{~mm}$; type IIIb: $>4 \mathrm{~mm}$ ). They found those without sinonasal disease (69.7\%) to be classified as type I, $24.9 \%$ as type II and $5.5 \%$ as type III.

Endoscopic sinus surgery can be associated with both minor and major complications (orbital emphysema, ec- chymosis, diplopia with temporary to permanent blindness) (4). The entry of Latrogenic to orbit through LP from the paranasal sinuses is the normal cause of orbital complications (5). The present research describes two cases with medial position and the dehiscence of LP.

\section{Case Presentation}

\subsection{Case I}

A 41-year-old male patient presented to the medical center with the complaint of postnasal discharge and allergic rhinitis without nasal obstruction, visual loss or diplopia. He had no history of head or face traumas or sinonasal surgery.

The CT scan of paranasal sinuses confirmed the involvement of the dehiscence and medialization of the LP of left side and bulla ethmoidalis. The distance from the MMA line to medial orbital wall was $12-13.4 \mathrm{~mm}$. The medial rectus muscle was intact and the orbital fat was entrapped (Figure 1).

\subsection{Case II}

A 60-year-old male patient with the complaint of chronic coughs, postnasal discharge and nasal congestion 

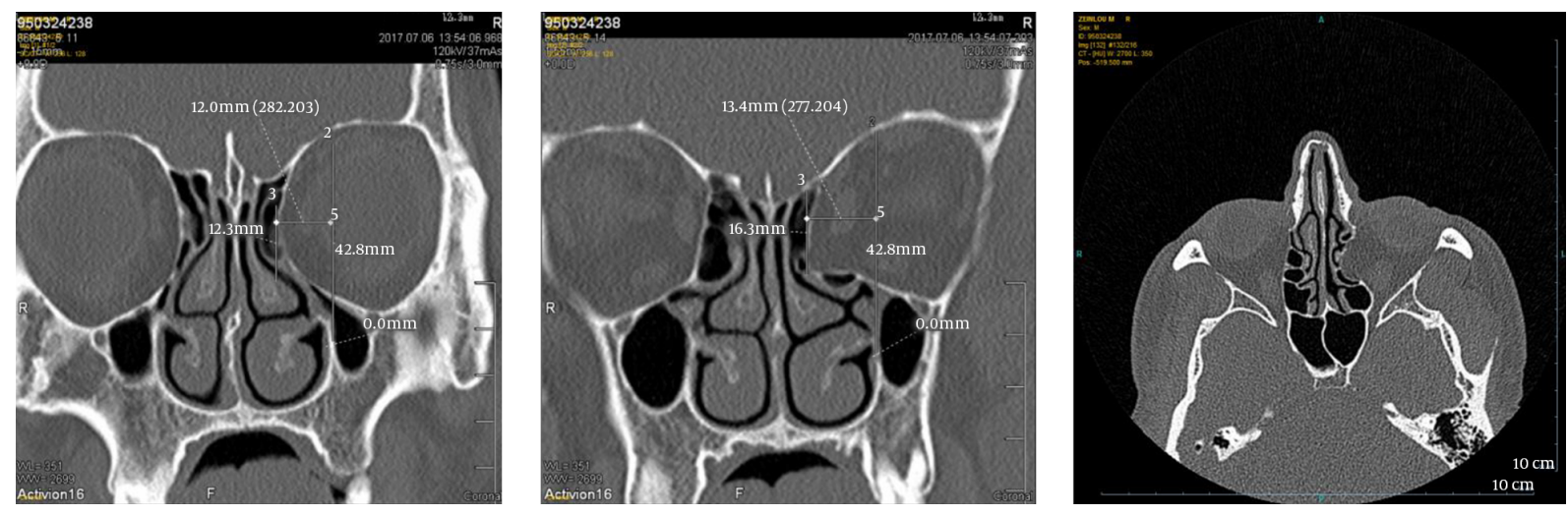

Figure 1. Paranasal sinus CT scan of the 41-year-old patient and his LP position

without visual loss or diplopia. He had no history of head or face trauma, sinonasal surgery and nasal obstruction.

The CT scan of paranasal sinus revealed the dehiscence and medialization of the LP of left side. The distance between the MMA and medial orbital wall was 10.8 - $13 \mathrm{~mm}$. Medial rectus muscle was intact and orbital fat was entrapped (Figure 2).

The CT examinations were performed with a 16-slice CT scan in Teb Azma Center in the city of Qom, Iran. The detector's width was $0.5 \mathrm{~mm}$, the section width $1.5 \mathrm{~mm}$ and the interval reconstruction $0.5 \mathrm{~mm}$ using $120 \mathrm{kV}$ and $50 \mathrm{~mA} / \mathrm{s}$ with a $1.5 \mathrm{~s}$ scan time wide window (widths about 1600 and levels about 500). The LP categorization was performed according to the procedure proposed by Herzella et al. (3). The LP position was therefore determined and found to be associated to the MMA line in the coronal image, which is a vertical line from the inferior turbinate to the medial maxillary wall. The distance of the LP midpoint was measured from this line (3).

\section{Discussion}

Paranasal sinuses and all turbinates arise from the cartilaginous nasal capsule (6). During the 3rd and 4th fetal months, the mucosa of nasal cavities evaginate and develop into paranasal sinuses. Maxillary and ethmoidal sinus are rudimentary at birth. Ethmoid cells are more developed anteriorly at birth with pneumatization progressively in a posterior direction and its growth lasting until late puberty (7). The anomaly of the paranasal sinuses has long been recognized, and refers to the dehiscence and medialization of LP. Hyrti (1) in 1869, Zuckerkandl in 1893 (1) and Sieur and Jacob in 1901 (8) performed skull dissection. They observed this variation in five cases of 200 skulls. There are certain other reports, including those provided by Kozlov(9) reporting 5.6\%, Zuckerlandl reporting 1.17\% (1) and Takahashi and Tsutsumi reporting 10\% (10).

Moulin revealed that if lateral part had been filled by the mass arising from the orbit (1) on dissecting sections, the ethmoid bullae in dehiscent cases were very small. The ethmoid mucosa was shown to separate this fatty mass from the aerated cavities (1). In the present cases, bulla ethmoidalis was involved and posterior ethmoid cells and medial rectus were intact while only the ethmoid mucosa was separated from the aerated cavities with orbital fat, and no entrapment was observed.

In 1987, Teatini et al. (11) showed a small gap in LP with no fat entrapment. Chow and Mafee (12) reported prolapse of medial rectus into the ethmoid cells. In 2016, On Moulin et al. (1), Kitaguchi et al. (13) found all the patients to be asymptomatic, limited to the anterior ethmoid sinus with fat prolapse, while one of the six patients had an opacified ethmoid sinus. The gap in the bone wall and the presence of fat in the bulla cells are the key diagnostic features. In the present cases, medial rectus was intact and no entrapment of muscle was observed.

Being aware of the dehiscence of LP is crucial before sinus surgery, since misdiagnosis may make perforation of orbital wall and damage the medial rectus and superior oblique hematoma and ocular infections $(11,14)$.

\subsection{Conclusion}

Variations of paranasal sinuses are common and some of them are very important; for instance, the position of LP (abnormal medial or latter position) or the dehiscence of LP. Being aware of these variations can prevent complications of orbit in sinus surgery. 

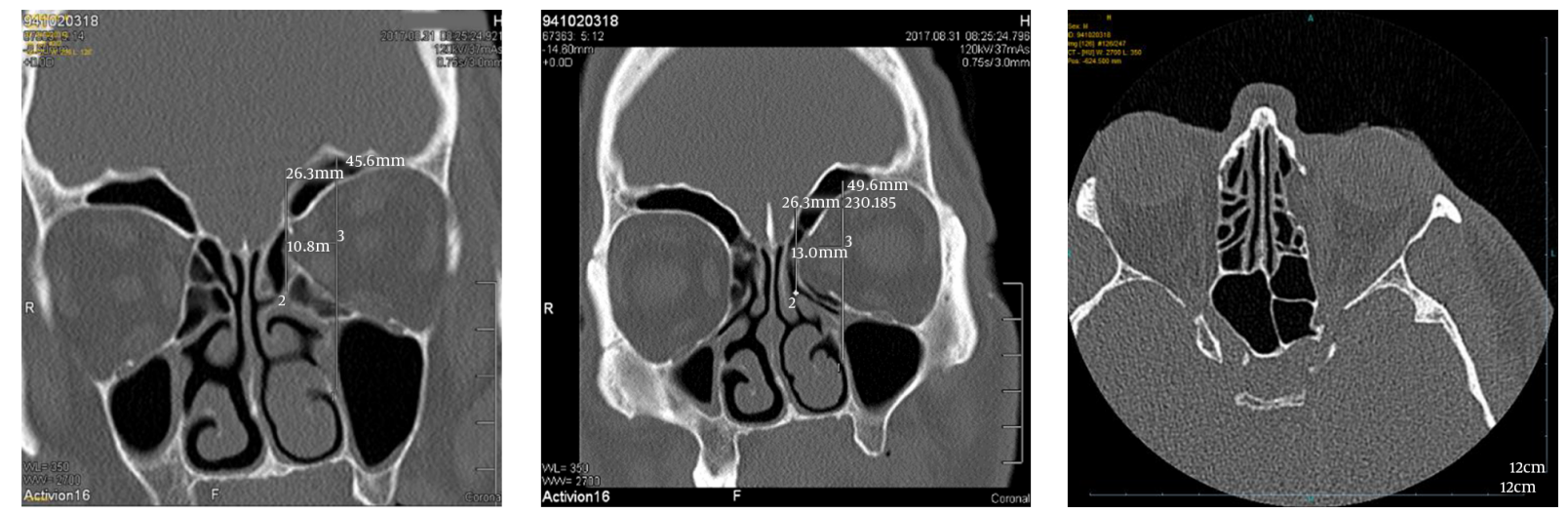

Figure 2. Paranasal sinus CT scan of the 60-year-old patient and his LP position

\section{Acknowledgments}

The authors would like to express their gratitude to Dr. Zahra Rezaii, radiologist, and Mahdi Hajmobini, specialist radiologist, the Teb Azma Center's staff for providing critical comments on the manuscript and Hossein Alizade for contributing to the correction of the manuscript translation.

\section{Footnotes}

Conflict of Interests: There are no conflict of interest among the authors.

Ethical Considerations: The inform consent was gained from patients.

Funding/Support: None declared.

\section{References}

1. Moulin G, Dessi P, Chagnaud C, Bartoli JM, Vignoli P, Gaubert JY, et al. Dehiscence of the lamina papyracea of the ethmoid bone: CT findings. AJNR Am J Neuroradiol. 1994;15(1):151-3. [PubMed: 8141047].

2. Meyers RM, Valvassori G. Interpretation of anatomic variations of computed tomography scans of the sinuses: A surgeon's perspective. Laryngoscope. 1998;108(3):422-5. [PubMed: 9504618].

3. Herzallah IR, Marglani OA, Shaikh AM. Variations of lamina papyracea position from the endoscopic view: A retrospective computed tomography analysis. Int Forum Allergy Rhinol. 2015;5(3):263-70. doi: 10.1002/alr.21450. [PubMed: 25413027].

4. Graham SM, Nerad JA. Orbital complications in endoscopic sinus surgery using powered instrumentation. Laryngoscope. 2003;113(5):874-8. doi: 10.1097/00005537-200305000-00018. [PubMed: 12792325].
5. Bhatti MT, Stankiewicz JA. Ophthalmic complications of endoscopic sinus surgery. Surv Ophthalmol. 2003;48(4):389-402. [PubMed: 12850228].

6. Som PM, Naidich TP. Illustrated review of the embryology and development of the facial region, part 1: Early face and lateral nasal cavities. AJNR Am J Neuroradiol.2013;34(12):2233-40. doi: 10.3174/ajnr.A3415. [PubMed: 23493891].

7. Korkmaz H, Korkmaz M. Total aplasia of the paranasal sinuses. Allergy Rhinol (Providence). 2013;4(2):e105-9. doi:10.2500/ar.2013.4.0056. [PubMed: 24124636]. [PubMed Central: PMC3793112].

8. Terrier F, Weber W, Ruefenacht D, Porcellini B. Anatomy of the ethmoid: CT, endoscopic, and macroscopic. AJR Am J Roentgenol. 1985;144(3):493-500. doi: 10.2214/ajr.144.3.493. [PubMed: 3871558].

9. Kozlov VN. [Anatomical data on the endonasal opening of the cells of the ethmoidal labyrinth]. Vestn Otorinolaringol.1975;(6):76-9. Russian. [PubMed: 1209858].

10. Takahashi R, Tsutsumi M. Nasal cavity reconstruction. Otolaryngology (Tokyo) (Jibi Inkoka). 1969;10:746-9.

11. Teatini G, Simonetti G, Salvolini U, Masala W, Meloni F, Rovasio S, et al. Computed tomography of the ethmoid labyrinth and adjacent structures. Ann Otol Rhinol Laryngol. 1987;96(3 Pt 1):239-50. doi: 10.1177/000348948709600301. [PubMed: 3605945].

12. Chow JM, Mafee MF. Radiologic assessment preoperative to endoscopic sinus surgery. Otolaryngol Clin North Am. 1989;22(4):691-701. [PubMed: 2771413].

13. Kitaguchi Y, Takahashi Y, Mupas-Uy J, Kakizaki H. Characteristics of dehiscence of lamina papyracea found on computed tomography before orbital and endoscopic endonasal surgeries. J Craniofac Surg. 2016;27(7):e662-5. doi: 10.1097/SCS.0000000000003005. [PubMed: 27536917].

14. Freedman HM, Kern EB. Complications of intranasal ethmoidectomy: A review of 1000 consecutive operations. Laryngoscope. 1979;89(3):421-34. doi: 10.1288/00005537-197903000-00010. [PubMed: 431247]. 